\title{
Child and Home Predictors of Children's Name Writing
}

\author{
Hope K. Gerde, Lori E. Skibbe, Ryan P. Bowles, and Tiffany L. Martoccio \\ Human Development \& Family Studies, Michigan State University, 552 W. Circle Drive, East Lansing, MI 48824, USA \\ Correspondence should be addressed to Hope K. Gerde, hgerde@msu.edu
}

Received 13 September 2012; Revised 13 November 2012; Accepted 16 November 2012

Academic Editor: Annie Vinter

Copyright ( 12012 Hope K. Gerde et al. This is an open access article distributed under the Creative Commons Attribution License, which permits unrestricted use, distribution, and reproduction in any medium, provided the original work is properly cited.

\begin{abstract}
The current study used dominance analysis to investigate the relative importance of multiple factors on children's (ages 3-5; mean age of 47.3 months) name writing skill when they enter preschool. Children $(n=103)$ were tested individually at the beginning of preschool on six factors thought to be important for name writing success: letter knowledge, decoding, motor skills, problem behaviors, self-regulation, and home literacy environment. Collectively, these variables explained $37.1 \%$ of the variation in children's name writing, but the importance of each factor differed widely. Children's knowledge of capital letters (11.8\%) and their motor development (11.8\%) were the most important for children's name writing whereas the home learning environment $(2.3 \%)$ and reported problem behaviors $(1.5 \%)$ were the least important factors. These findings suggest that researchers and teachers should focus on letter knowledge and motor development in understanding and promoting children's name writing skills.
\end{abstract}

\section{Introduction}

Recent policy reports $[1,2]$ identify emergent writing, the period of time in which a child begins to understand the function of writing and early writing skills develop, as an important aspect of children's literacy development. Previous longitudinal research has identified the importance of emergent writing for predicting other literacy skills well into elementary school. For example, children's emergent writing in kindergarten predicted later literacy skills, such as decoding, spelling, and reading comprehension in first grade [3] and spelling in second grade [4]. Moreover, previous research has identified emergent writing skills to be a key predictor of later reading ability $[5,6]$.

One very important aspect of emergent writing is a child's ability to write his or her own name. Names provide a consistent source of letters for children to practice writing [7] and often represent children's first writing attempts [8]. Preschoolers vary considerably in their ability to write their name [9-11], and this variation is related to other important aspects of early literacy development such as word recognition [12] and letter knowledge [13, 14]. Furthermore, the National Early Literacy Panel [2] specifically notes that children's ability to write their name in preschool predicts later literacy achievement, highlighting the importance of this facet of writing for young children.

1.1. Factors Related to the Development of Writing. In light of the importance of emergent writing, and specifically name writing, in the development of literacy, it is important to understand what most effectively promotes or inhibits successful development of name writing. Although previous work has called for research to identify the critical predictors that contribute to children's development of name writing [15], highlighting this work as a serious gap in the literature, to date, research has focused narrowly on literacy skills as predictors of emergent writing for preschoolers, with a particular emphasis on letter knowledge and decoding [12, 1417]. Young children's name writing, similar to other aspects of literacy [18], may rely not just on related literacy skills, but also on other important aspects of children's physical and social development. Comprehensive work with schoolage children by Berninger and her colleagues (see [19] for a review) found that writing is multidimensional, relying on motor, orthographic coding [20], vocabulary knowledge [21, 
22] and working memory [23]. However, despite numerous studies considering preschool children's name writing as a predictor and precursor to literacy development, no study has examined which skills preschoolers rely upon most to write their names. To address this gap, we use dominance analysis [24] to examine the relative importance of factors that are theoretically important for name writing: letter knowledge, decoding, motor skills, problem behaviors, and behavioral self-regulation. In addition, we include a measure of the home literacy environment because previous work has found that, for young children, engaging in more literacy activities at home is related to higher scores on measures of literacy skills $[25,26]$.

1.1.1. Letter Knowledge. The relation between name writing and letter knowledge is well established [12, 16, 17, 27]. For example, Molfese et al. [16] and Justice et al. [28] identified significant correlations between name writing and letter knowledge. One study of 3,546 prekindergarten children [14] found that age, letter knowledge, and print knowledge accounted for $34 \%$ of the variation in children's name writing. In addition, children analyze letter patterns when learning to write, suggesting that children rely on their letter knowledge (versus letter-sound awareness) initially when working to write $[29,30]$.

1.1.2. Decoding. Recent work has identified a relation between children's name writing and their ability to decode words $[4,16]$. For example, Molfese and colleagues [31] found that children's name writing at the beginning of preschool was significantly correlated with children's decoding skills $(r=.42)$. Theoretically, understanding that letters can be combined to convey meaning is important for both decoding and name writing [32], and children develop some early decoding skills prior to becoming writers, so it is likely that young children need early decoding skills to engage in name writing.

1.1.3. Fine-Motor Skills. Although to our knowledge, relations between name writing and fine-motor skills have not been examined for preschoolers, previous work has identified a positive relation between children's fine-motor development and cognitive development more generally [33-35]. Preschool-age children use their fine-motor skills to explore their environment, initiate social interactions, engage in play, and develop basic academic skills [36, 37]. Prekindergarten children's fine-motor performance is generally related to reading and language achievement in first grade $[38,39]$. Son and Meisels [35] found that, in K-1 grades, reading achievement is better predicted by fine-motor skills and cognitive skills than by either skill alone. And, although the relation between fine-motor and reading skills is longitudinal, we do not know how these skills are related in preschool and specifically for name writing development versus broader reading achievement. Also, children who have problems with language acquisition and attention skills often have impaired fine-motor function early in life [40-42], and many of these same children also exhibit difficulties in writing [43, 44].
Regarding name writing specifically, Berninger and Graham [45] suggest that naming a letter is likely to serve as a cue for retrieving the motor program for writing that letter, which, in turn, facilitates the writing process. Thus, the present study examines the predictive value of fine-motor skills on preschool children's name writing development.

1.1.4. Problem Behaviors. Previous work has identified lower literacy outcomes for children who exhibit problem behaviors in preschool [46]. One explanation for the lower literacy achievement among children who exhibit behavior problems is that children with externalizing behavior problems, such as inattention and aggression, are less likely to stay on task [47] and benefit from learning opportunities, like name writing instruction, provided in the classroom [48]. The task of writing one's name requires practice, persistence, and focused attention [49]. Children who exhibit externalizing problem behaviors may lack necessary persistence and attention and therefore have less experience with name writing tasks. Thus, it seems plausible that children with externalizing problem behaviors may have difficulty with name writing. The present study investigates the predictive value of problem behaviors on children's name writing development.

1.1.5. Behavioral Self-Regulation. Another child's characteristic associated with children's literacy development in general is their behavioral self-regulation [18, 50]. Among preschoolers, self-regulation encompasses aspects of emotional and behavioral regulation that help children to plan and manage their behavior as well as pay attention to the task at hand [51]. More specifically, self-regulation involves physiological processes [52], cognitive processes such as working memory, attention, and inhibitory control [5355], as well as emotional processes [53], and these skills also appear to be crucial for writing $[19,49]$. At least for older children, previous work has found that one aspect of self-regulation, poor working memory, acts as a constraint to writing production [56, 57]. This may be true for younger children too as self-regulation predicts children's early literacy skills in preschool [51], although effects are sometimes small [51] and have not been consistent across studies $[55,58]$. Thus, understanding the degree to which self-regulation affects children's name writing in particular may provide additional insight into which skills are the most important for supporting children's name writing development.

1.1.6. Home Learning Environment. Although sometimes considered to be less important than children's own characteristics [59], parents do work to promote children's literacy development at home, implicitly through their provision of educational materials (e.g., books and writing materials; [60]) and through explicit instruction of literacy forms and functions $[61,62]$. Importantly, parents who engage in more literacy activities at home with their children have children with better developed literacy skills $[25,26,63]$. Both formal home literacy practices, such as direct teaching of letters, as well as informal ones, such as storybook reading, appear to 
be beneficial for children's literacy development, although literacy practices promote facets of children's development differentially [26]. Numerous studies have investigated how mothers can work to facilitate children's writing of their name $[64,65]$ and how such interactions relate to the writing skills of older Chinese [66] and Israeli [67] children. However, this relation has not been studied directly with a US sample of preschoolers. Clearly, this collection of studies suggests that it is important to include in our model a measure of home learning as a predictor of children's name writing $[25,68]$. The present study examines the contribution of the home learning environment on children's name writing skills at preschool entry.

1.2. Current Study. In summary, based on a careful review of the literature, we have identified six factors related to children's behavior and their environment that are theoretically important to the development of name writing skills: letter knowledge, decoding, motor skills, behavior problems, behavioral self-regulation, and parent report of home literacy environment. The relative importance of these factors, however, is not known; that is, it is not clear which of the six factors is the most important predictor of name writing skills, which is least important, and so forth. Statistical studies have established that this is not a simple question [69]. Although simple approaches such as zero-order correlations and patterns of statistical significance within a multiple regression can provide some indications of relative importance, these types of statistical tests can be misleading when variables are multicollinear. The present study uses dominance analysis $[24,70]$ to study the relative importance of multiple independent variables as predictors of children's name writing. Relative importance is defined as "the proportionate contribution each predictor makes to $R^{2}$, considering both its direct effect (i.e., its correlation with the criterion) and its effect when combined with the other variables in the regression equation" [69, page 240]. Dominance analysis ranks multicollinear predictors according to their importance and decomposes the total variance explained $\left(R^{2}\right)$ into relative contributions of each predictor [70]. This study therefore provides a greater understanding of the nature of name writing, allows researchers to ascertain the most fruitful directions for further understanding of children's name writing, and supports practitioners' efforts to pinpoint and intervene on aspects of children's behavior and environment that are most likely to support children's progress in name writing skills.

\section{Method}

2.1. Participants. Children $(n=103)$ were recruited from two preschools in a Midwestern state. Children's average age at the beginning of the study was 47.35 months ( $\mathrm{SD}=$ 7.84 months; range $=37-61$ months). The sample included 59 boys and 44 girls. Of the 80 families who completed a demographic questionnaire, children's race/ethnicity was reported to be predominantly Caucasian $(n=64)$, although African American $(n=3)$ and Asian $(n=13)$ children were represented as well. Mothers were well educated, with most $(n=68)$ having attained at least a bachelor's degree.

2.2. Procedure. At the beginning of the school year, trained research assistants collected child measures in a quiet place at children's schools and teachers collected children's writing samples as a part of typical classroom instruction. Also, in the late fall teachers completed a questionnaire about each child's classroom behavior at a time convenient to the teacher (i.e., outside of class time) and parents completed questionnaires about their home literacy practices.

\subsection{Measures}

2.3.1. Name Writing. Consistent with other work in the field $[10,12-14]$, children's emergent writing was captured using a name writing task. Children begin writing with name writing $[8,71]$, and name writing is an appropriate assessment for young preschoolers including three- and four-year-old children (e.g., [11]). Classroom teachers were trained in a systematic process for gathering children's name writing data and offered no assistance to children during this task. Specifically, each child was instructed to write his/her name on a blank piece of paper and prompted to "write as much asv you can."

Children's name writing was coded into 9 categories of increasing sophistication adapted from the work of Sulzby et al. [72], ranging from minimal knowledge of letters (refusal to write: "1," scribbling: "2," and drawing as writing: " 3 ") to writing strategies that reflect conventional writing (i.e., scribble writing: " 4 ", letter-like shapes: " 5 ", and writing combining at least one letter and letter-like shapes: " 6 "). The final three categories demonstrated the child's use of letters when writing their name (writing includes 2 or more letters and does not include letter-like shapes: "7"; all name letters are written but in incorrect order: " 8 " and correct spelling of the first name: "9"). Following Yaden and Tardibuono's [73] observation that young children's writing may be difficult to decipher, we credit any recognizable letter (including letter reversals) as a letter. This approach to evaluating children's writing is similar to the approach used by Bloodgood [12], Diamond et al. [13], and Sulzby et al. [72].

In addition, the writing was judged on whether it was horizontal (i.e., less than 45 degrees in curvature; 0: not horizontal, 1: horizontal), linear (0: n/a, 1: scattered, 2: linear), and used case appropriately (0: n/a, 1: all letters capital, 2: first letter capital and some but not all others lowercase, and 3: first letter capital and all others lowercase). Scores on these process codes were added to the sophistication code to establish the total name writing score, which was used in analyses (range: 1-15). Three research assistants were trained to code name writing until each reached $k=.95$. Twentyfive percent of the name writing samples were double coded with interrater reliability maintained above $k=.90$ for both aspects of the scale.

The number of letters in children's first name varied (range: 3-9 letters) although $76 \%$ of names written had 
4-6 letters. Note that we accepted nicknames (e.g., Abby for Abigail) in addition to full names when employing this coding system. Correlation analysis indicated that there is only a small and nonsignificant correlation between name length and writing score $(r=-.18, P=.07)$. Further, name length was uncorrelated with all the predictor variables included in the model, so that it only adds error variance to the dominance analysis.

2.3.2. Letter Knowledge. Children's letter knowledge was assessed using flashcards each depicting one unique capital letter of the alphabet presented in random order. When each flashcard appeared, children were asked to name the letter on the flashcard. Children scored a " 0 " if they incorrectly identified the letter or a " 1 " if they correctly identified the letter (possible scoring range: 0-26; coefficient alpha $=.97$ ).

2.3.3. Decoding. Children's decoding skills were measured using the Woodcock-Johnson Tests of Achievement LetterWord Identification subtest [74]. This test requires children initially to identify capital and lowercase letters, then to choose target words from a group of words, and to read real words with increasing difficulty. Basal and ceiling guidelines for the subtest indicated that testing should stop after the child answered six consecutive items incorrectly. In our analyses, we used $\mathrm{W}$ scores, a conversion of raw scores to Rasch ability scales [75], with a W score of 500 representing the average achievement level for a 10 -year-old child and 314 representing the norm for a 48 months [74]. Although all children begin this task by identifying letters, only $11 \%$ of children achieved a ceiling without reaching word identification items. Reliability for this subscale is .92 .

2.3.4. Fine-Motor Skills. Children's fine-motor skills were assessed using the Motor subtest of the Early Screening Inventory-Revised (ESI-R; [76]). Previous work has used this well-established, standardized developmental screening test to identify preschool and kindergarten children who may be at risk for school failure $[77,78]$ and to assess fine-motor development for research purposes [35]. The task consists of a block-building item, four shape-copying items, and a person-drawing item. The block-building item required children to use five blocks to build a gate either by model or imitation; children received 2 points for building a gate by model, 1 point for building a gate by imitation, and 0 for not building a gate either way. The shape-copying items involved copying various shapes (circle, cross, square, and triangle) from an illustration. Children received 1 point for each shape drawn successfully. Finally, in the person-drawing item, children received 2 points if their drawing included 5 or more body parts, 1 point if their drawn person had 3 or 4 body parts, and 0 points if their drawing had less than 3 body parts. Thus, scores on the fine-motor subtest ranged from 0 to 8. Meisels et al. [76] found test-retest reliability for the ESI$\mathrm{R}$ to be .89 . Interitem reliability for the fine-motor subscale was .57 [79].
2.3.5. Problem Behaviors. Using the Social Skills Rating System-Teacher form (SSRS; [80]), teachers provided information about children's problem behaviors. This measure consists of 10 questions in which teachers rated children on their frequency of engagement in specific behaviors using a three-point scale (never: "0", sometimes: "1", and very often: "2"). We used the externalizing behaviors subset (6 questions) of the Total Problem Behaviors scale (e.g., "Has temper tantrums") as these were the most relevant theoretically to children's name writing. Scores for the externalizing behaviors subset range between 0 to 12; note that high scores indicate a child's high expression of problem behaviors whereas low scores indicate a lack of or low expression of problem behaviors. According to Gresham and Elliott [80], coefficient alpha was .82 for the Total Problem Behaviors scale.

2.3.6. Self-Regulation. The Head-Toes-Knees-Shoulders (HTKS; $[51,55,58,77])$ task was used as a direct measure of behavior regulation (including working memory, attention, inhibitory control, and task persistence). The HTKS, which has been linked to literacy achievement in preschool $[18,50,51]$, consists of two sections. In the first section, children were taught two oral commands ("touch your head" and "touch your toes"). They were then asked to do the opposite of what the researcher said. For example, if the researcher instructed the child to touch his/her head, the child must do the opposite and touch his/her toes. In the second section, two additional opposing commands were added ("touch your knees" and "touch your shoulders"). Responses were scored as 0 (incorrect), 1 (self-correct) (i.e., child changed an incorrect response to a correct one with no help from the administrator), or 2 (correct). Higher scores indicate higher levels of self-regulation (scores range $0-40$ ). Recent work demonstrates strong reliability and validity of the HTKS $[81,82]$. As one example, scores on the Head-to-Toes task correlated with scores on items designed to measure behavioral regulation as assessed by the Child Behavior Rating Scale $(r=.46, P<.001$, [51]). The self-regulation task is difficult for young children and, thus, resulted in several scores of 0 , causing a high standard deviation in our sample. To deal with this issue, we conducted the analyses with and without the children scoring 0 . Results were not substantively different, so we have maintained the full sample including the children with 0 scores.

2.3.7. Home Learning Environment. Parents completed The Parenting Questionnaire [83], which asks about parenting beliefs and practices and has been linked to literacy achievement in preschool [84]. For the present study, only the home learning environment dimension, which included seven items (e.g., "(1) How frequently do you teach your child the names of letters?, (2) How frequently do you teach your child letter sounds?, (3) How frequently do you teach your child to read words?, (4) How frequently do you encourage your child to write?, (5) I try to provide my child with math workbooks, (6) My child and I play number games such as 
“This Old Man" or "1, 2, Buckle My Shoe", (7) I encourage my child to do math-related activities, such as connect-thenumber pictures, mazes, and puzzles"), was used. For items $1-4$, parents scored the frequency with which they engaged in the activity from 1 (almost never) to 5 (daily). For items $5-7$, parents were asked to rate the degree to which a given behavior described their parenting from 1 (not at all like me) to 5 (very much like me) (scores range from 7-35). Previous work with parents of kindergarten children [83] demonstrated coefficient alpha reliability of .75. The current sample produced a coefficient alpha reliability of .78.

2.4. Analytical Approach. The present study used dominance analysis $[24,70]$ to provide a valid means for establishing relative importance among a set of collinear predictors of children's name writing skills; in the current study, we examined the unique contributions from each of the six individual predictors (i.e., letter knowledge, decoding, motor skills, problem behaviors, self-regulation, and children's home learning environment). Dominance analysis works by considering a factor's strength of prediction individually, in the context of all other factors and in the context of all possible subsets of the other factors. We focused on each factor's contribution to the overall $R^{2}$. We also considered 3 forms of dominance as described by Azen and Budescu [85]: a factor completely dominates another factor if it is a stronger predictor in every potential subset model in the dominance analysis; a factor conditionally dominates another factor if its average contribution to $R^{2}$ across models within a subset size (i.e., number of predictors within a model) is higher for every subset size; a factor generally dominates if it, on average, contributes more to the $R^{2}$ across all models and subset sizes. To deal with missing data among the six predictors (rates ranged from $4 \%$ for letter name knowledge to $11 \%$ for home learning environment), we used multiple imputation with 100 imputations. We ran the dominance analysis on each data set, averaging the overall $R^{2}$, each predictor's proportion of $R^{2}$, and the level of dominance (1: dominates other factor, 0 : is dominated by other factor, .5: no dominance between factors). We also created $95 \%$ confidence intervals for the $R^{2}$ values by bootstrapping 1000 samples from each of the imputations (for a total of 100,000 bootstrap samples), averaging the lower and upper bounds across the 100 imputations. The analyses were completed in SAS using adaptations of Azen's macros [24, 86, 87]. The SAS script is available upon request. More technical details about dominance analysis are available in Azen and Budescu [85] and Johnson and LeBreton [69].

\section{Results}

At preschool entry, the children in the present sample were able to, on average, write their name using letters and letterlike shapes $(32 \%)$ with a linear directionality. However, there was substantial variability in the sample, as several children used scribbles $(26 \%)$ and some children used drawing (2\%), scribble writing (2\%), and letter-like shapes $(8 \%)$ to write their name. Still others wrote their name using all letters with
TABLE 1: Descriptive Information for Children.

\begin{tabular}{lc}
\hline Variable & $(N=103)$ \\
\hline Ethnicity & $3(3.0 \%)$ \\
$\quad$ African American & $64(62.1 \%)$ \\
Caucasian & $13(12.6 \%)$ \\
Asian & $23(22.3 \%)$ \\
$\quad$ Not indicated/did not respond & \\
Gender & $59(57.3 \%)$ \\
Boys & $44(42.7 \%)$ \\
Girls & \\
Maternal education & $6(5.8 \%)$ \\
High school diploma or less & $7(6.8 \%)$ \\
Some college or a two-year degree & $32(31 \%)$ \\
Bachelor's degree & $36(35 \%)$ \\
Graduate or professional work & $22(21.4 \%)$ \\
Not indicated/did not respond & $47.35(7.84)$ \\
Child mean age in months (SD) & $8.81(5.07)$ \\
Mean writing (SD) & $25.61(5.31)$ \\
Mean home learning environment (SD) & $5.72(2.06)$ \\
Mean fine-motor skills (SD) & $344.01(32.48)$ \\
Mean decoding (SD) & $15.46(9.83)$ \\
Mean capital letter knowledge (SD) & $10.65(13.02)$ \\
Mean self-regulation (SD) & $96.69(11.91)$ \\
Mean problem behavior (SD) &
\end{tabular}

incorrect spelling (3\%) or correct spelling (22\%). Children knew approximately 15 uppercase letters at the beginning of the year (Range: $0-26, S D=9.83$ ) and had relatively high scores in decoding for their age (Mean $=344.01, \mathrm{SD}=$ 32.48; Woodcock-Johnson norm for 48 months is 314 [74]). On average, children scored $5.72(\mathrm{SD}=2.06)$ on the finemotor task, consistent with the ability to build a gate with small blocks, successfully copy a circle and cross, and draw a person with 3-4 parts. On average, children scored 10.65 $(\mathrm{SD}=13.02)$ in behavioral self-regulation on a scale of $1-40$. These scores were similar to previous work using the same measure in preschool classrooms (Mean $=10.02, \mathrm{SD}=8.01$; 82). Typically, parents provided multiple home supports for learning (Mean $=25.61, \mathrm{SD}=5.31$ ) indicating, on average, that 4-5 of the 7 learning behaviors were "very much like me" or that they engaged in the activity "daily". See Table 1 for descriptive statistics of all variables.

Zero-order correlations revealed significant $(P<.05)$ positive relations between children's name writing and their knowledge of letter names $(r=.47)$, decoding skill $(r=$ $.35)$, fine-motor skill $(r=.44)$, and self-regulatory ability $(r=.23)$ at the beginning of preschool. Name writing was not significantly correlated with teachers' report of problem behaviors $(r=-.15)$ or the home learning environment $(r=.17)$. (See Table 2 for a complete matrix of correlations.)

3.1. Dominance Analysis. The overall $R^{2}$ for the six factors predicting name writing scores was .371. Two predictors were clearly the most important: letter name knowledge and fine-motor skills each accounted for .118 of the $R^{2}$. 
TABLE 2: Correlations between measures of children's development, teachers' report of problem behaviors, and parents' report of home literacy environment.

\begin{tabular}{|c|c|c|c|c|c|c|}
\hline & 1 & 2 & 3 & 4 & 5 & 6 \\
\hline (1) Capital letter knowledge & - & & & & & \\
\hline (2) Fine-motor skills & $.37 * *$ & - & & & & \\
\hline (3) Woodcock-Johnson Letter-Word ID & $.77^{* *}$ & $.38^{* *}$ & 一 & & & \\
\hline (4) Teacher SSRS: problem behaviors & $-.21^{*}$ & -.20 & $-.24^{*}$ & - & & \\
\hline (5) Home literacy environment & $.50^{* *}$ & $.31^{* *}$ & $.35^{* *}$ & -.18 & - & \\
\hline (6) Head-Toes-Knees-Shoulders task & $.30 * *$ & $.40^{* *}$ & $.23^{*}$ & $-.25^{*}$ & .15 & - \\
\hline (7) Name writing & $.47^{* *}$ & $.44^{* *}$ & $.35^{* *}$ & -.15 & .17 & $.23^{*}$ \\
\hline
\end{tabular}

TABLE 3: Dominance values results for dominance analysis of predictors of children's name writing.

\begin{tabular}{|c|c|c|c|c|c|c|}
\hline Predictor & $\begin{array}{c}\text { Letter } \\
\text { knowledge }\end{array}$ & Decoding & $\begin{array}{c}\text { Fine-motor } \\
\text { skills }\end{array}$ & $\begin{array}{c}\text { Problem } \\
\text { behaviors }\end{array}$ & $\begin{array}{c}\text { Behavioral } \\
\text { self-regulation }\end{array}$ & $\begin{array}{c}\text { Home literacy } \\
\text { env. }\end{array}$ \\
\hline \multicolumn{7}{|c|}{ Complete dominance } \\
\hline Letter knowledge & - & .97 & .49 & 1.00 & 1.00 & .99 \\
\hline Decoding & .03 & - & .22 & .63 & .59 & .54 \\
\hline Fine-motor skills & .52 & .78 & - & 1.00 & 1.00 & 1.00 \\
\hline Problem behaviors & .00 & .38 & .00 & - & .44 & .50 \\
\hline Behavioral self-regulation & .00 & .41 & .00 & .56 & - & .51 \\
\hline Home literacy environment & .01 & .47 & .00 & .50 & .49 & - \\
\hline \multicolumn{7}{|c|}{ Conditional dominance } \\
\hline Letter knowledge & - & .98 & .47 & 1.00 & 1.00 & .99 \\
\hline Decoding & .02 & - & .16 & .72 & .75 & .54 \\
\hline Fine-motor skills & .54 & .84 & - & 1.00 & 1.00 & 1.00 \\
\hline Problem behaviors & .00 & .29 & .00 & - & .30 & .35 \\
\hline Behavioral self-regulation & .00 & .25 & .00 & .70 & - & .49 \\
\hline Home literacy environment & .01 & .46 & .00 & .66 & .51 & 一 \\
\hline \multicolumn{7}{|c|}{ General dominance } \\
\hline Letter knowledge & - & .97 & .52 & 1.00 & 1.00 & 1.00 \\
\hline Decoding & .03 & - & .08 & 1.00 & 1.00 & 1.00 \\
\hline Fine-motor skills & .48 & .92 & - & 1.00 & 1.00 & 1.00 \\
\hline Problem behaviors & .00 & .00 & .00 & - & .07 & .09 \\
\hline Behavioral self-regulation & .00 & .00 & .00 & .93 & - & .56 \\
\hline Home literacy environment & .00 & .00 & .00 & .91 & .44 & - \\
\hline
\end{tabular}

Values are the proportion of analyses in which row factor dominates column factor. Types of dominance are defined in the text.

In other words, out of the total variance explained, both letter name knowledge and fine-motor skills accounted for $31.8 \%$ $(=.118 / .371)$. As indicated in Table 3, both factors almost always exhibited all forms of dominance with all other factors except each other. Decoding was a little more than half as important: decoding accounted for .070 of the $R^{2}(18.9 \%$ of the total); decoding almost always generally dominated the other factors and more often than not completely and conditionally dominated as well. Finally, a third tier of predictors were of limited importance; the home literacy environment accounted for only .023 (6.3\% of the total), externalizing problem behaviors accounted for .015 (4.1\% of the total) and self-regulation accounted for only .026 of the $R^{2}\left(7.1 \%\right.$ of the total). Results for $R^{2}$ are summarized in Table 4 .
In an effort to be as comprehensive as possible, we considered two alternative models when examining predictors of children's name writing development. First, we considered a dominance analysis without decoding because our measures of letter knowledge and decoding overlapped somewhat in content. Regardless of whether we included decoding in the model, results were quite similar. The overall $R^{2}$ for the five-factor model predicting name writing scores was .354 . Letter name knowledge accounted for a greater proportion of the $R^{2}(44.7 \%=.158 / .354)$, reflecting the variance shared with decoding. The other variables were similar in relative importance: fine-motor skills, 35.4\%; home learning environment, $7.1 \%$; externalizing problem behaviors, $4.6 \%$; selfregulation, $8.1 \%$. Thus, decoding explains variation beyond that of letter knowledge alone. Second, we examined the 
TABLE 4: $R^{2}$ Results for dominance analysis of predictors of children's name writing.

\begin{tabular}{lccc}
\hline Predictor & $R^{2}$ Contribution & $95 \%$ Confidence interval & Proportion of overall $R^{2}$ \\
\hline Letter knowledge & .118 & {$[.044, .218]$} & $31.8 \%$ \\
Decoding & .070 & {$[.024, .137]$} & $18.9 \%$ \\
Fine-motor skills & .118 & {$[.036, .226]$} & $31.8 \%$ \\
Problem behaviors & .015 & {$[.001, .058]$} & $4.1 \%$ \\
Behavioral self-regulation & .026 & {$[.004, .077]$} & $7.1 \%$ \\
Home literacy environment & .023 & {$[.008, .052]$} & $6.3 \%$ \\
\hline
\end{tabular}

effect of age on the results by repeating the dominance analysis controlling for age. We regressed the writing score on a child's age and used the residual as the outcome variable in the dominance analysis. Patterns of results did not differ substantially, although there was relatively more error variance because reliable variance associated with age was removed. Note that controlling for age removes variance from the writing scores that is of fundamental importance to the goals of the study, as it takes away variance that would help us to understand why older children had higher writing scores than younger children. Thus, we do not include age in the final model.

\section{Discussion}

The present study suggests that there is a large amount of variability in how children write their names when they begin preschool. Results indicate that many factors (i.e., knowledge of capital letters, fine-motor skill, decoding skill, teachers' report of problem behaviors, home learning environment, and children's self-regulation) explained a substantial proportion of the variance in children's name writing skills; however, the relative contribution made by each factor varied greatly. Specifically, children's knowledge of capital letters and fine-motor skills explained the most variance in children's name writing, followed by children's decoding skill. Children's home learning environment, teachers' report of problem behaviors, and children's ability to regulate their own behaviors accounted for only a small amount of the variation.

There was considerable variability in the nature of children's name writing during preschool. Consistent with previous findings $[9,10,13,15,88]$ preschoolers vary in the forms they use for writing their name; all nine categories of name writing development from scribbling to writing their name correctly were represented in the current sample. Further, directionality, linearity, and accurate case were observed as well. On average, at preschool entry, children in our middleSES sample as well as those in the low-SES sample reported on by Diamond and her colleagues [13] wrote their name using letter-like shapes and letters. It is notable that, across both samples, a majority of children did not write their name accurately at the beginning of the year. Twenty-two percent of our middle-SES sample wrote their name correctly at the beginning of the year that, which is comparatively more than the $7 \%$ of low-SES children reported to write their name accurately in previous work [13], but, still indicates that this skill is not mastered by most preschoolers in the fall of the school year.

4.1. Letter Knowledge. As expected, variability in name writing was predicted by the six factors examined in the present study; however two factors, letter knowledge and fine-motor skills, stood out as more important predictors of name writing than the other factors analyzed in the present study. Letter knowledge is well established as an important predictor of name writing ability $[12,14,28]$. This study adds to previous research by identifying letter knowledge not merely as an important predictor but as the most important predictor of the factors we studied. Clearly, children's knowledge of capital letters helps them to write their names.

4.2. Fine-Motor Skills. Our results also suggest that finemotor skills are one of the most important predictors of this aspect of early literacy development. Research with older children has found orthographic coding [20] and graphomotor planning for sequential finger movements [22] to predict children's writing for first through sixth graders [21]. This study extends this previous research to establish fine-motor skills as a predictor of name writing with younger children, a finding that, although not necessarily surprising, has not as yet been established empirically.

A unique and notable contribution of this study is that fine-motor skills are not just a predictor but among the strongest predictors of name writing skills for young children. It is well known that fine-motor skills help children to spatially organize marks on the page and manipulate their fine-motor muscles in a way to produce specific, differentiated shapes $[21,88]$. This is particularly true for children who are attempting to form letters (i.e., specific, differentiated shapes made of multiple lines, circles, and curves). Results from the current study demonstrate that young children without well-developed fine-motor skills are at a clear disadvantage for executing name writing. This study highlights that fine-motor skills should receive more attention in research on the development of writing specifically and literacy skills more generally.

4.3. Decoding. Children's decoding skills accounted for a moderate amount of the variance $(7 \%)$ in children's name writing, even with letter knowledge included in the model. 
Although some researchers [10] have argued that name writing is primarily a mechanical skill, more like drawing than writing [89] and does not reflect a conceptual understanding of letter sounds, letter patterns, or letterword identification, our results indicate that these skills are important for children's name writing. In addition, research suggests that once children can write their names, teachers use children's names as a basis for making letter-sound connections to other words (e.g., comparing initial sounds in names of classmates and other non-name words beginning with the same sound [12]); thus, decoding may be even more important for words beyond the child's own name. Certainly, the direction of the relation between decoding and name writing deserves further investigation. Nevertheless, our results suggest that the fundamental skills associated with decoding (e.g., letter-sound correspondence) are important for acquiring the skills needed to write one's own name.

4.4. Problem Behaviors. Teachers' report of children's externalizing problem behaviors explained very little of the variance $(1.5 \%)$ in children's name writing skills. In the present study, the most prevalent problem behaviors were associated with inattention and aggression. Specifically, when teachers noted a problem behavior, they were most likely to say that children fidgeted excessively, disobeyed requests, and argued with others. These types of problem behaviors may interfere with children's ability to take advantage of classroom instruction [48], although results from the present study suggest that problem behaviors are not too important, as compared to other factors, when considering children's name writing specifically.

4.5. Behavioral Self-Regulation. Children's observed selfregulation explained a small amount of the variance in children's name writing skill in the fall of the preschool year $(2.6 \%)$. Although zero-order correlations identified a significant relation between children's self-regulation and their name writing ability, similar to other studies $[18,50]$, self-regulation explained only a small amount of unique variation in children's name writing when other, presumably more important variables were included in the model. This suggests that being able to regulate one's behavior is less important than other factors for preschool children's name writing.

4.6. Home Learning Environment. Similar to previous work, which indicates that child characteristics are more strongly predictive of children's early literacy skills than what parents do with their children at home [59], the nature of the home learning environment as described by parents accounted for less variance $(2.3 \%)$ than many of the child factors examined in the current study. It is important to note that parents tend to engage in some types of learning practices more than others, which may affect the strength of results in the present study. In particular, parents often favor activities such as storybook reading over direct literacy instruction, including formal instruction in the area of name writing [90]. Research suggests that specific instruction may be necessary to support children's name writing $[65,88,91]$, which may be one reason why this factor was less predictive of name writing than other factors studied in the current study. Also, the home learning environment data presented here were based on parent report of their practices. An observational measure of parents' supports for writing specifically, may have been a stronger predictor (e.g., $[66,67]$ ) and should be considered in future work.

4.7. Implications. These findings have important theoretical and educational implications for understanding the role of name writing in the development of literacy. With the inclusion of name writing as an important indicator of children's early literacy achievements in recent reports $[1,2]$, it is important to consider what information researchers and educators gain when asking children to engage in name writing. If, as the current study suggests, fine-motor skills explain a substantial amount of the variance in children's name writing, then early literacy measures which use name writing may not be assessing only literacy skills but rather a combination of skills which, according to our study, includes not just literacy, but also physical abilities. The strong predictive value of name writing may therefore reflect, at least in part, a role of fine-motor skills in reading. Son and Meisels [35] argue that fine-motor skills assessment in combination with cognitive assessment may increase our ability to predict general cognitive achievement for K1 graders; this may also be true for preschoolers. Thus, reading measures avoiding fine-motor skills and pedagogy intended to bypass the use of fine-motor movement (e.g., touch screen technology versus writing) may be missing an important aspect of literacy development. For example, one intervention study found training preschoolers to write (versus training to type) resulted in higher emergent literacy scores [92]. Today, writing is frequently not produced using a pen or pencil. However, we do not yet understand the potential consequences of bypassing the act of writing in favor of technologically mediated print-communication processes (e.g., typing, touchscreen) for children's literacy and cognitive development [92]. This possibility has received little attention in the literature and is a matter for future research.

On the other hand, fine-motor skills may interfere with the expression of name writing and its prediction of later reading abilities. Although name writing is identified as a developmentally appropriate activity for preschool children $[11,93]$, it is possible that some children lack the fine-motor skills necessary to demonstrate their knowledge of writing. Such considerations may be doubly important for those with known fine-motor difficulties, such as children with autism [94-96], Down syndrome [97, 98], or cerebral palsy $[99,100]$, to name a few. These children may know more about the literacy processes involved in writing (e.g., print concepts, letter knowledge) than their fine-motor skills allow them to express. If this barrier were removed or accounted for (via the use of technology, for example), name writing may prove to be an even stronger predictor of reading that should receive more attention in research on literacy development. If this is the case, interventions targeting fine-motor 
skills and/or letter knowledge may be needed to maximize the usefulness of name writing in literacy development. This possibility needs to be examined empirically, especially as some studies have found limited associations between finemotor functions and reading [101].

Educators interested in supporting children's letter knowledge and fine-motor skills as potential avenues for enhancing children's writing efforts should provide writing activities that allow children to manipulate writing tools to form letters in meaningful ways (e.g., sign up for computer use or take an order in the dramatic play restaurant). There is evidence that teaching letter names and letter sounds simultaneously helps children to develop early decoding skills $[102,103]$. There may be an added value to including name writing in these activities, because writing draws children's attention to letter names and shapes, which helps children to distinguish between these abstract entities [32].

4.8. Limitations and Future Directions. Several limitations should be considered for the present study. Only $10 \%$ of participants resided in low-income households and the majority of mothers held at least a bachelor's degree. In addition, participants were recruited from a university laboratory school, with accreditation from the National Association for the Education of Young Children and teachers with a Master's degree in child development/early childhood education, two markers identifying the high quality of the program. Thus, it is unclear how results from the present study would generalize to a more at-risk population of children or to children served by preschool programs with lower quality.

In addition, although name writing is a common way to examine children's writing skills [12-14, 17], it has been argued that name writing represents a fundamentally different type of skill than other types of writing $[10,89]$. Some researchers suggest the skills children use to write their name are more similar to those they use when drawing a picture than to writing words other than their name and therefore do not involve advanced decoding skills such as sound-letter connections or a conceptual understanding of letters $[10,89]$. Future work should investigate whether these factors predict other types of children's writing differentially.

Finally, we note that, although the measures used in the current study were chosen because of their relations with early literacy skills in other studies, the results must be interpreted in light of the factors we included and the regression model underlying dominance analysis. As with any statistical approach, results may vary somewhat if our constructs were measured in a different way and/or other factors were considered (e.g., phonological awareness). The system of relations among these constructs is likely complex and may include bidirectional relations among skills $[104,105]$. This study provides a first examination of how important child and home variables relate to children's name writing at preschool entry utilizing an innovative data analysis technique to identify relative importance among predictors. More research, including longitudinal studies, is needed to parse out the direction and causal nature of these and other factors underlying name writing and other forms of early writing.

\section{Conclusion}

Given the value of name writing to later reading $[2,5]$, this study highlights the need to view name writing as a compilation of many skills, including both literacy skills (e.g., letter knowledge) and skills outside the domain of literacy. The innovative use of dominance analysis applied here allows for the identification of the most essential predictors of young children's name writing. Of the factors examined in the present study, children's fine-motor skills and knowledge of capital letters were the most important for explaining variance in children's name writing. Decoding was of moderate importance, while the home literacy environment, externalizing problem behaviors, and behavioral self-regulation were less important. Thus, name writing is a complex task for young children requiring many skills but particularly expertise in letter knowledge and sophisticated fine-motor skills.

\section{References}

[1] National Early Literacy Panel, Developing Early Literacy: Report of the National Early Literacy Panel, National Institute for Literacy, Washington, DC, USA, 2004.

[2] National Early Literacy Panel, Developing Early Literacy: Report of the National Early Literacy Panel, National Institute for Literacy, Washington, DC, USA, 2008.

[3] E. Shatil, D. L. Share, and I. Levin, "On the contribution of kindergarten writing to grade 1 literacy: a longitudinal study in Hebrew," Applied Psycholinguistics, vol. 21, no. 1, pp. 1-21, 2000.

[4] D. Aram, "Continuity in children's literacy achievements: a longitudinal perspective from kindergarten to school," First Language, vol. 25, no. 3, pp. 259-289, 2005.

[5] D. D. Hammill, "What we know about correlates of reading," Exceptional Children, vol. 70, no. 4, pp. 453-468, 2004.

[6] C. E. Snow, M. S. Burns, and P. Griffin, Eds., Preventing Reading Difficulties in Young Children, National Academy Press, Washington, DC, USA, 1998.

[7] L. Tolchinsky, "The emergence of writing," in Handbook of Writing Research, C. A. MacArthur, S. Graham, and J. Fitzgerald, Eds., pp. 83-95, Guilford Press, New York, NY, USA, 2006.

[8] M. M. Clay, What Did I Write? Heinemann Educational Books, Portsmouth, NH, USA, 1975.

[9] S. Q. Cabell, L. M. Justice, T. A. Zucker, and A. S. McGinty, "Emergent name-writing abilities of preschool-age children with language impairment," Language, Speech, and Hearing Services in Schools, vol. 40, no. 1, pp. 53-66, 2009.

[10] M. Drouin and J. Harmon, "Name writing and letter knowledge in preschoolers: incongruities in skills and the usefulness of name writing as a developmental indicator," Early Childhood Research Quarterly, vol. 24, no. 3, pp. 263270, 2009.

[11] C. S. Puranik and C. J. Lonigan, "From scribbles to scrabble: preschool children's developing knowledge of written language," Reading and Writing, vol. 24, no. 5, pp. 567-589, 2011. 
[12] J. W. Bloodgood, "What's in a name? Children's name writing and literacy acquisition," Reading Research Quarterly, vol. 34, no. 3, pp. 342-367, 1999.

[13] K. E. Diamond, H. K. Gerde, and D. R. Powell, "Development in early literacy skills during the pre-kindergarten year in Head Start: relations between growth in children's writing and understanding of letters," Early Childhood Research Quarterly, vol. 23, no. 4, pp. 467-478, 2008.

[14] J. G. Welsch, A. Sullivan, and L. M. Justice, "That's my letter!: what preschoolers' name writing representations tell us about emergent literacy knowledge," Journal of Literacy Research, vol. 35, pp. 757-776, 2003.

[15] C. S. Puranik, C. J. Lonigan, and Y. Kim, "Contributions of emergent literacy skills to name writing, letter writing, and spelling in preschool children," Early Childhood Research Quarterly, vol. 26, pp. 465-474, 2011.

[16] V. J. Molfese, J. Beswick, A. Molnar, and J. Jacobi-Vessels, "Alphabetic skills in preschool: a preliminary study of letter naming and letter writing," Developmental Neuropsychology, vol. 29, no. 1, pp. 5-19, 2006.

[17] R. Treiman and V. Broderick, "What's in a name: children's knowledge about the letters in their own names," Journal of Experimental Child Psychology, vol. 70, no. 2, pp. 97-116, 1998.

[18] M. M. McClelland, F. J. Morrison, and D. L. Holmes, "Children at risk for early academic problems: the role of learningrelated social skills," Early Childhood Research Quarterly, vol. 15, no. 3, pp. 307-329, 2000.

[19] V. Berninger, "Highlights of programmatic, interdisciplinary research on writing," Learning Disabilities. Research and Practice, vol. 24, pp. 68-79, 2009.

[20] V. W. Berninger, C. Yates, and K. Lester, "Multiple orthographic codes in reading and writing acquisition," Reading and Writing, vol. 3, no. 2, pp. 115-149, 1991.

[21] V. W. Berninger, A. C. Cartwright, C. M. Yates, H. L. Swanson, and R. D. Abbott, "Developmental skills related to writing and reading acquisition in the intermediate gradesshared and unique functional systems," Reading and Writing, vol. 6, no. 2, pp. 161-196, 1994.

[22] V. Berninger, C. Yates, A. Cartwright, J. Rutberg, E. Remy, and R. Abbott, "Lower-level developmental skills in beginning writing," Reading and Writing, vol. 4, no. 3, pp. 257-280, 1992.

[23] H. L. Swanson and V. W. Berninger, "Individual differences in children's writing: a function of working memory or reading or both processes?" Reading and Writing, vol. 8, no. 4, pp. 357-383, 1996.

[24] R. Azen and D. V. Budescu, "Comparing predictors in multivariate regression models: an extension of dominance analysis," Journal of Educational and Behavioral Statistics, vol. 31, no. 2, pp. 157-180, 2006.

[25] M. Hood, E. Conlon, and G. Andrews, "Preschool home literacy practices and children's literacy development: a longitudinal analysis," Journal of Educational Psychology, vol. 100, no. 2, pp. 252-271, 2008.

[26] M. Sénéchal and J. A. LeFevre, "Parental involvement in the development of children's reading skill: a five-year longitudinal study," Child Development, vol. 73, no. 2, pp. 445-460, 2002.

[27] R. Blair and R. Savage, "Name writing but not environmental print recognition is related to letter-sound knowledge and phonological awareness in pre-readers," Reading and Writing, vol. 19, no. 9, pp. 991-1016, 2006.
[28] L. M. Justice, M. Invernizzi, K. Geller, A. K. Sullivan, and J. Welsch, "Descriptive-developmental performance of at-risk preschoolers on early literacy tasks," Reading Psychology, vol. 26, no. 1, pp. 1-25, 2005.

[29] V. Berninger, "Normal variation in reading acquisition," Perceptual and Motor Skills, vol. 62, pp. 691-716, 1986.

[30] S. A. Vernon and E. Ferreiro, "Writing development: a neglected variable in the consideration of phonological awareness," Harvard Educational Review, vol. 69, no. 4, pp. 395415, 1999.

[31] V. J. Molfese, J. L. Beswick, J. L. Jacobi-Vessels et al., "Evidence of alphabetic knowledge in writing: connections to letter and word identification skills in preschool and kindergarten," Reading and Writing, vol. 24, no. 2, pp. 133-150, 2011.

[32] M. M. Clay, Change Over Time in Children's Literacy Development, Heinemann Educational Books, Portsmouth, NH, USA, 2001.

[33] A. Diamond, "Close interrelation of motor development and cognitive development and of the cerebellum and prefrontal cortex," Child Development, vol. 71, no. 1, pp. 44-56, 2000.

[34] P. Liljestrand, R. J. Jeremy, Y. W. Wu, D. M. Ferriero, G. J. Escobar, and T. B. Newman, "Use of the motor performance checklist to study motor outcomes in 5-year-olds," Journal of Paediatrics and Child Health, vol. 45, no. 6, pp. 368-374, 2009.

[35] S. H. Son and S. J. Meisels, "The relationship of young children's motor skills to later reading and math achievement," Merrill-Palmer Quarterly, vol. 52, no. 4, pp. 755-778, 2006.

[36] National Research Council Committee on Early Childhood Pedagogy, Eager to Learn: Educating Our Preschoolers, National Academy Press, Washington, DC, USA, 2001.

[37] E. J. Gibson, "Perceptual learning in development: some basic concepts," Ecological Psychology, vol. 12, no. 4, pp. 295-302, 2000.

[38] H. A. Solan and R. Mozlin, "The correlations of perceptualmotor maturation to readiness and reading in kindergarten and the primary grades," Journal of the American Optometric Association, vol. 57, no. 1, pp. 28-35, 1986.

[39] P. H. Wolff, C. Gunnoe, and C. Cohen, "Neuromotor maturation and psychological performance: a developmental study," Developmental Medicine and Child Neurology, vol. 27, no. 3, pp. 344-354, 1985.

[40] C. Amiel-Tison, C. Njiokiktjien, L. Vaivre-Douret, C. A. Verschoor, E. Chavanne, and M. Garel, "Relation of early neuromotor and cranial signs with neuropsychological outcome at 4 years," Brain and Development, vol. 18, no. 4, pp. 280-286, 1996.

[41] M. H. Cantell, M. M. Smyth, and T. P. Ahonen, "Clumsiness in adolescence: educational, motor, and social outcomes of motor delay detected at 5 years," Adapted Physical Activity Quarterly, vol. 11, no. 2, pp. 115-129, 1994.

[42] S. S. Hamilton, "Evaluation of clumsiness in children," American Family Physician, vol. 66, no. 8, pp. 1435-1440, 2002.

[43] M. E. Delano, "Improving written language performance of adolescents with asperger syndrome," Journal of Applied Behavior Analysis, vol. 40, no. 2, pp. 345-351, 2007.

[44] T. O. Lienemann and R. Reid, "Using self-regulated strategy development to improve expository writing with students with attention deficit hyperactivity disorder," Exceptional Children, vol. 74, no. 4, pp. 471-486, 2008.

[45] V. Berninger and S. Graham, "Language by hand: a synthesis of a decade of research in handwriting," Handwriting Review, vol. 12, pp. 11-25, 1998. 
[46] R. J. Bulotsky-Shearer and J. W. Fantuzzo, "Preschool behavior problems in classroom learning situations and literacy outcomes in kindergarten and first grade," Early Childhood Research Quarterly, vol. 26, no. 1, pp. 61-73, 2011.

[47] R. B. Howse, S. D. Calkins, A. D. Anastopoulos, S. P. Keane, and T. L. Shelton, "Regulatory contributions to children's kindergarten achievement," Early Education and Development, vol. 14, pp. 101-120, 2003.

[48] G. J. Duncan, C. J. Dowsett, A. Claessens et al., "School readiness and later achievement," Developmental Psychology, vol. 43, no. 6, pp. 1428-1446, 2007.

[49] H. S. Mäki, M. J. M. Voeten, M. M. S. Vauras, and E. H. Poskiparta, "Predicting writing skill development with word recognition and preschool readiness skills," Reading and Writing, vol. 14, no. 7-8, pp. 643-672, 2001.

[50] L. E. Smith, J. G. Borkowski, and T. L. Whitman, "From reading readiness to reading competence: the role of selfregulation in at-risk children," Scientific Studies of Reading, vol. 12, no. 2, pp. 131-152, 2008.

[51] M. M. McClelland, C. E. Cameron, C. M. Connor, C. L. Farris, A. M. Jewkes, and F. J. Morrison, "Links between behavioral regulation and preschoolers' literacy, vocabulary, and math skills," Developmental Psychology, vol. 43, no. 4, pp. 947-959, 2007.

[52] J. C. Pruessner, O. T. Wolf, D. H. Hellhammer et al., "Free cortisol levels after awakening: a reliable biological marker for the assessment of adrenocortical activity," Life Sciences, vol. 61, no. 26, pp. 2539-2549, 1997.

[53] C. Blair and A. Diamond, "Biological processes in prevention and intervention: the promotion of self-regulation as a means of preventing school failure," Development and Psychopathology, vol. 20, no. 3, pp. 899-911, 2008.

[54] M. B. Bronson, Self-Regulation in Early Childhood: Nature and Nurture, Guilford Press, New York, NY, USA, 2000.

[55] C. C. Ponitz, M. M. McClelland, J. S. Matthews, and F. J. Morrison, "A structured observation of behavioral selfregulation and its contribution to kindergarten outcomes," Developmental Psychology, vol. 45, no. 3, pp. 605-619, 2009.

[56] B. Bourdin and M. Fayol, "Is graphic activity cognitively costly? A developmental approach," Reading and Writing, vol. 13, pp. 183-196, 2000.

[57] J. R. Hayes and N. A. Chenoweth, "Is working memory involved in the transcribing and editing of texts?" Written Communication, vol. 23, no. 2, pp. 135-149, 2006.

[58] J. S. Matthews, C. C. Ponitz, and F. J. Morrison, "Early gender differences in self-regulation and academic achievement," Journal of Educational Psychology, vol. 101, no. 3, pp. 689704, 2009.

[59] A. H. Hindman, L. E. Skibbe, A. Miller, and M. Zimmerman, "Ecological contexts and early learning: contributions of child, family, and classroom factors during Head Start, to literacy and mathematics growth through first grade," Early Childhood Research Quarterly, vol. 25, no. 2, pp. 235-250, 2010.

[60] J. Roberts, J. Jurgens, and M. Burchinal, "The role of home literacy practices in preschool children's language and emergent literacy skills," Journal of Speech, Language, and Hearing Research, vol. 48, no. 2, pp. 345-359, 2005.

[61] K. K. Bennett, D. J. Weigel, and S. S. Martin, "Children's acquisition of early literacy skills: examining family contributions," Early Childhood Research Quarterly, vol. 17, no. 3, pp. 295-317, 2002.

[62] L. M. Justice and H. K. Ezell, "Enhancing children's print and word awareness through home-based parent intervention,"
American Journal of Speech-Language Pathology, vol. 9, no. 3, pp. 257-269, 2000.

[63] L. E. Skibbe, L. M. Justice, T. A. Zucker, and A. S. McGinty, "Relations among maternal literacy beliefs, home literacy practices, and the emergent literacy skills of preschoolers with specific language impairment," Early Education and Development, vol. 19, no. 1, pp. 68-88, 2008.

[64] D. Aram, "Joint writing in Hebrew of dictated words versus proper names: analysis of low SES mother-kindergartner dyads," Journal of Research in Childhood Education, vol. 17, pp. 47-61, 2002.

[65] D. Aram, T. Most, and A. Ben Simon, "Early literacy of kindergartners with hearing impairment: the role of motherchild collaborative writing," Topics in Early Childhood Special Education, vol. 28, no. 1, pp. 31-41, 2008.

[66] D. Lin, C. McBride-Chang, D. Aram, H. Shu, I. Levin, and J. Cho, "Maternal mediation of word writing in Chinese across Hong Kong and Beijing," Journal of Educational Psychology, vol. 104, pp. 121-137, 2012.

[67] O. Korat and I. Levin, "Maternal beliefs, mother-child interaction, and child's literacy: comparison of independent and collaborative text writing between two social groups," Journal of Applied Developmental Psychology, vol. 22, no. 4, pp. 397-420, 2001.

[68] S. A. Storch and G. J. Whitehurst, "The role of family and home in the literacy development of children from low-income backgrounds," New Directions for Child and Adolescent Development, vol. 2001, no. 92, pp. 53-71, 2001.

[69] J. W. Johnson and J. M. LeBreton, "History and use of relative importance indices in organizational research," Organizational Research Methods, vol. 7, no. 3, pp. 238-257, 2004.

[70] D. V. Budescu, "Dominance analysis: a new approach to the problem of relative importance of predictors in multiple regression," Psychological Bulletin, vol. 114, no. 3, pp. 542-551, 1993.

[71] I. Levin, A. Both-de Vries, D. Aram, and A. Bus, "Writing starts with own name writing: from scribbling to conventional spelling in Israeli and Dutch children," Applied Psycholinguistics, vol. 26, no. 3, pp. 463-477, 2005.

[72] E. Sulzby, J. Barnhart, and J. Hieshima, "Forms of writing and rereading from writing: A preliminary report," in Reading and Writing Connections, J. Mason, Ed., pp. 31-63, Allyn and Bacon, Needham Heights, Mass, USA, 1989.

[73] D. B. Yaden Jr. and J. M. Tardibuono, "The emergent writing development of urban Latino preschoolers: developmental perspectives and instructional environments for secondlanguage learners," Reading \& Writing Quarterly, vol. 20, pp. 29-61, 2004.

[74] R. W. Woodcock and N. Mather, Woodcock Johnson III Tests of Achievement: Examiner's Manual, Riverside, Itasca, Ill, USA, 2001.

[75] G. Rasch, Probabilistic Models for Some Intelligence and Attainment Tests, Danish Institute for Educational Research, Copenhagen, Denmark, 1960.

[76] S. J. Meisels, D. B. Marsden, M. S. Wiske, and L. W. Henderson, Early Screening Inventory (ESI), Rebus, Ann Arbor, Mich, USA, 1997.

[77] E. Kimmel, "Review of the early sscreening inventoryrevised," in The Fourteenth Mental Measurements Yearbook, B. S. Plake and J. C. Impara, Eds., pp. 450-451, Buros Institute of Mental Measurements of the University of NebraskaLincoln, Lincoln, Mass, USA, 2001. 
[78] K. D. Paget, "Review of the early screening inventoryrevised," in The Fourteenth Mental Measurements Yearbook, S. B. Plake and J. C. Impara, Eds., pp. 451-453, Buros Institute of Mental Measurements of the University of NebraskaLincoln, Lincoln, Mass, USA, 2001.

[79] National Center for Education Statistics, ECLS-K Base Year Public-Use Data Files and Electronic Codebook, National Center for Education Statistics, Washington, DC, USA, 2001.

[80] F. M. Gresham and S. N. Elliott, Social Skills Rating System, American Guidance Service, Circle Pines, Minn, USA, 1990.

[81] C. M. Connor, F. J. Morrison, B. J. Fishman, C. Schatschneider, and P. Underwood, "The early years: algorithm-guided individualized reading instruction," Science, vol. 315, no. 5811, pp. 464-465, 2007.

[82] C. C. Ponitz, M. M. McClelland, A. M. Jewkes, C. M. Connor, C. L. Farris, and F. J. Morrison, "Touch your toes! developing a direct measure of behavioral regulation in early childhood," Early Childhood Research Quarterly, vol. 23, pp. 141-158, 2008.

[83] F. Morrison and R. Cooney, "Parenting and academic achievement: multiple paths to early literacy," in Parenting and the Children's World: Influences on Academic, Intellectual, and Social-Emotional Development, J. Borkowski, S. Ramey Landesman, and M. Bristol-Power, Eds., pp. 141-160, Lawrence Erlbaum Associates, Mahwah, NJ, USA, 2002.

[84] A. H. Hindman and F. J. Morrison, "Differential contributions of three parenting dimensions to preschool literacy and social skills in a middle-income sample," Merrill-Palmer Quarterly, vol. 58, pp. 191-223, 2012.

[85] R. Azen and D. V. Budescu, "The dominance analysis approach for comparing predictors in multiple regression," Psychological Methods, vol. 8, no. 2, pp. 129-148, 2003.

[86] R. Azen, "Dominance analysis SAS macros," 2010, https:// pantherfile.uwm.edu/azen/www/damacro.html.

[87] SAS Institute, "SAS/GRAPH Software," Reference Volume 1, Version 8, Cary, NC, USA, SAS Institute, 2002.

[88] E. Ferreiro and A. Teberosky, Literacy Before Schooling, Heinemann Educational Books, Portsmouth, NH, USA, 1982.

[89] I. Levin and A. G. Bus, "How is emergent writing based on drawing? Analyses of children's products and their sorting by children and mothers," Developmental Psychology, vol. 39, no. 5, pp. 891-905, 2003.

[90] M. Sénéchal, J. A. LeFevre, E. M. Thomas, and K. E. Daley, "Differential effects of home literacy experiences on the development of oral and written language," Reading Research Quarterly, vol. 33, no. 1, pp. 96-116, 1998.

[91] C. Wood, "Parent-child preschool activities can affect the development of literacy skills," Journal of Research in Reading, vol. 25, pp. 241-258, 2002.

[92] M. Longcamp, M. T. Zerbato-Poudou, and J. L. Velay, "The influence of writing practice on letter recognition in preschool children: a comparison between handwriting and typing," Acta Psychologica, vol. 119, no. 1, pp. 67-79, 2005.

[93] C. Copple and S. Bredekamp, Eds., Developmentally Appropriate Practice: In Early Childhood Programs Serving Children Birth Through Age Eight, NAEYC, Washington, DC, USA, 2008.

[94] J. L. Adrien, P. Lenoir, J. Martineau et al., "Blind ratings of early symptoms of autism based upon family home movies," Journal of the American Academy of Child and Adolescent Psychiatry, vol. 32, no. 3, pp. 617-626, 1993.
[95] G. T. Baranek, "Autism during infancy: a retrospective video analysis of sensory-motor and social behaviors at 912 months of age," Journal of Autism and Developmental Disorders, vol. 29, no. 3, pp. 213-224, 1999.

[96] J. E. Scharre and M. P. Creedon, "Assessment of visual function in autistic children," Optometry and Vision Science, vol. 69, no. 6, pp. 433-439, 1992.

[97] A. Jobling, "Attainment of motor proficiency in school-aged children with Down syndrome," Adapted Physical Activity Quarterly, vol. 16, no. 4, pp. 344-361, 1999.

[98] M. L. Latach, "Motor coordination in Down Syndrome: the role of adaptive changes," in Perceptual Motor Behavior in Down Syndrome, D. J. Weeks, R. Chua, and D. Elliott, Eds., pp. 199-221, Human Kinetics, Champaign, Ill, USA, 2000.

[99] K. G. Holt, J. P. Obusek, and S. T. Fonseca, "Constraints on disordered locomotion: a dynamical systems perspective on spastic cerebral palsy," Human Movement Science, vol. 15, no. 2, pp. 177-202, 1996.

[100] R. White, I. Agouris, R. D. Selbie, and M. Kirkpatrick, "The variability of force platform data in normal and cerebral palsy gait," Clinical Biomechanics, vol. 14, no. 3, pp. 185-192, 1999.

[101] F. Ramus, E. Pidgeon, and U. Frith, "The relationship between motor control and phonology in dyslexic children," Journal of Child Psychology and Psychiatry and Allied Disciplines, vol. 44, no. 5, pp. 712-722, 2003.

[102] S. B. Piasta, D. J. Purpura, and R. K. Wagner, "Fostering alphabet knowledge development: a comparison of two instructional approaches," Reading and Writing, vol. 23, no. 6, pp. 607-626, 2010.

[103] S. B. Piasta and R. K. Wagner, "Developing early literacy skills: a meta-analysis of alphabet learning and instruction," Reading Research Quarterly, vol. 45, no. 1, pp. 8-38, 2010.

[104] A. J. Sameroff and M. Chandler, "Transactional models in early social relations," Human Development, vol. 18, pp. 6579, 1975.

[105] A. J. Sameroff and M. J. Mackenzie, "Research strategies for capturing transactional models of development: the limits of the possible," Development and Psychopathology, vol. 15, no. 3, pp. 613-640, 2003. 


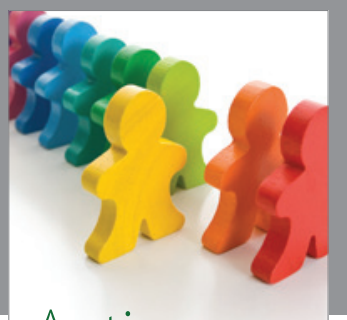

Autism

Research and Treatment
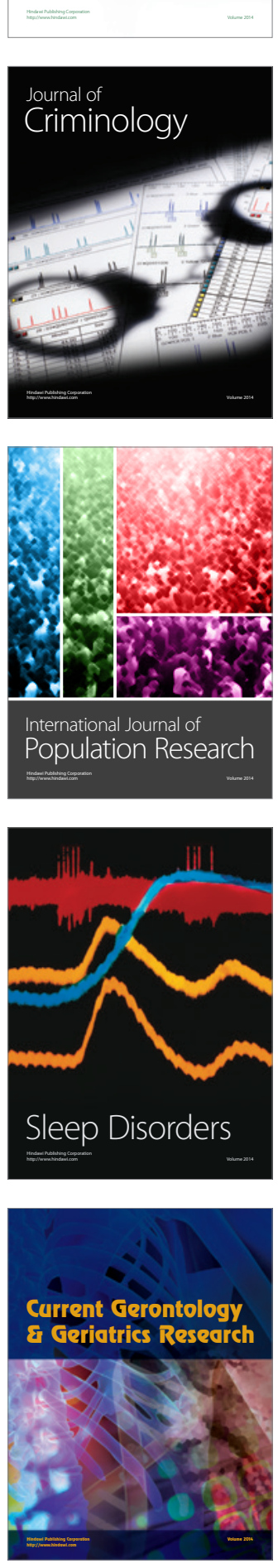
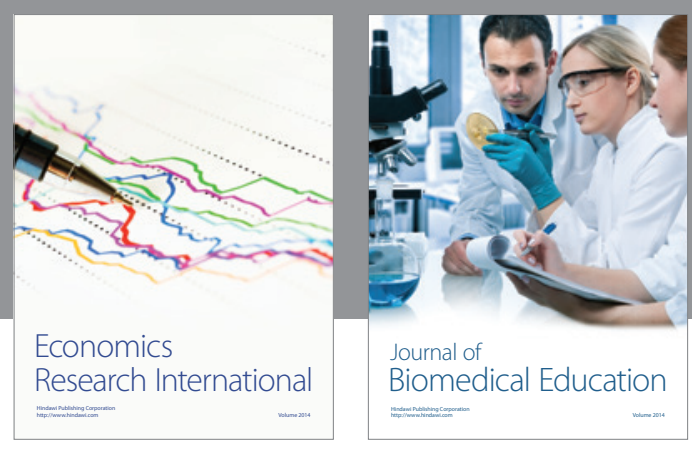

Journal of

Biomedical Education

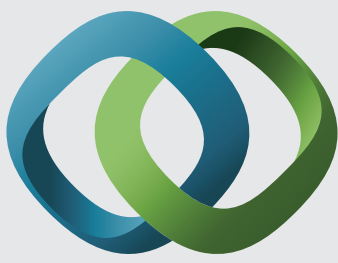

\section{Hindawi}

Submit your manuscripts at

http://www.hindawi.com
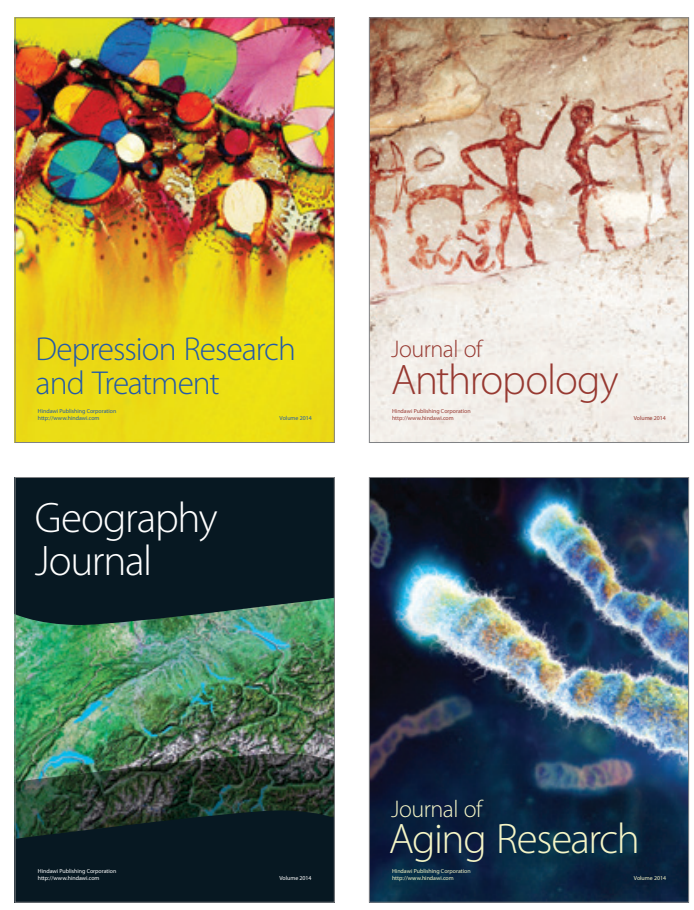

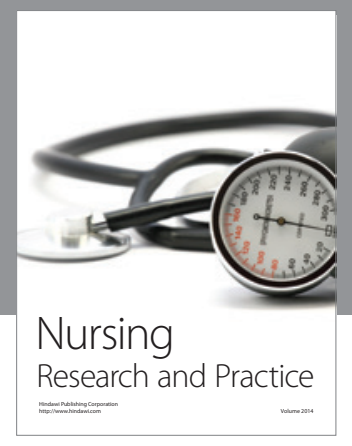

Nursing

Research and Practice

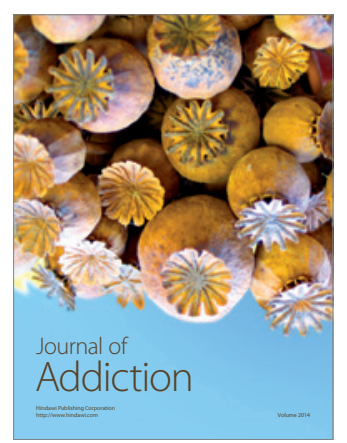

Child Development

Research

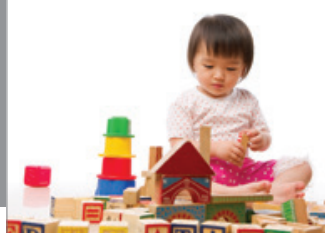

迥
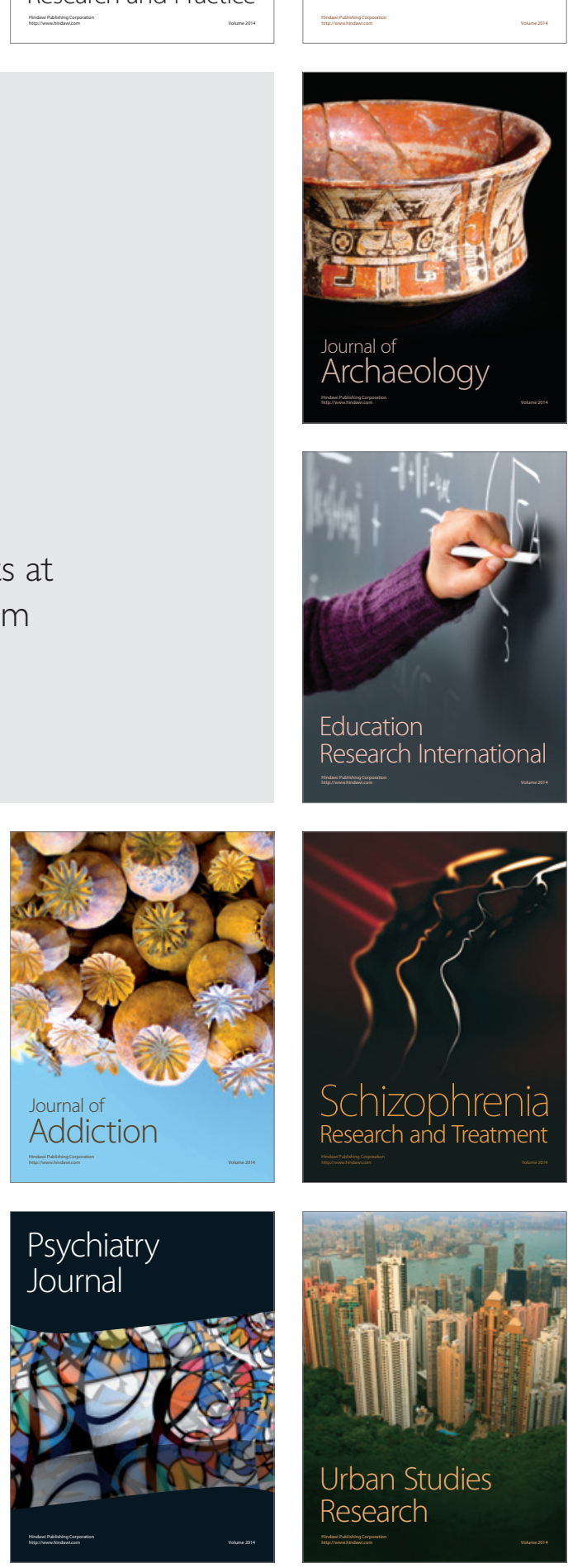